\title{
DETERMINAÇÃO DO GRAU DE UMIDADE DE SEMENTES DE IPÊ-DO-CERRADO Tabebuia ochracea ((Cham.) Standl.) PELOS MÉTODOS DE ESTUFA E FORNO DE MICROONDAS
}

\author{
Determination of the ipê-do-cerrado (Tabebuia ochracea (Cham.) Standl.) \\ seeds humidity degree by the greenhouse and microwave oven methods
}

\author{
Marcela Carlota Nery¹, Maria Laene Moreira de Carvalho², Luciana Magda de Oliveira ${ }^{3}$
}

\begin{abstract}
RESUMO
A utilização de métodos rápidos e eficientes para a determinação da umidade de sementes pode auxiliar na preservação de espécies florestais, já que a umidade é um dos fatores que mais influenciam no processo de deterioração de sementes dessas espécies. Com o objetivo de definir a metodologia adequada para a determinação da umidade de sementes de ipê-do-cerrado (Tabebuia ochracea (Cham.) Standl.), foram utilizados quatro lotes coletados na região de Machado - MG, determinando a umidade em duas etapas. Na $1^{\text {a }}$ etapa do experimento, foram testados os métodos de estufa a $105^{\circ} \mathrm{C} / 24 \mathrm{~h}$ e $103^{\circ} \mathrm{C} / 17 \mathrm{~h}$, com diferentes pesos das repetições e recipientes. $\mathrm{Na} 2^{\mathrm{a}}$ etapa, o método de estufa que propiciou menor variação entre repetições obtidas na $1^{\mathrm{a}}$ etapa foi comparado ao método do forno de microondas, utilizando diferentes procedimentos e tempos de exposição. Entre os métodos de estufa testados, o que possibilitou menor variação de resultados na determinação da umidade de sementes de ipê-do-cerrado foi o de $103^{\circ} \mathrm{C} / 17 \mathrm{~h}$, com utilização de cápsulas de alumínio e peso de sementes de um grama. As menores variações de resultados entre a metodologia de estufa $103^{\circ} \mathrm{C} / 17 \mathrm{~h}$ e forno de microondas ocorrem quando se utiliza o tempo de 5 minutos para determinação da umidade de sementes de ipê-do-cerrado.
\end{abstract}

Termos para indexação: Estufa, ipê-do-cerrado, teor de água, espécie florestal, microondas, Tabebuia ochracea.

\begin{abstract}
As humidity is one of the factors that most influence upon the process of seeds deterioration in forest species, the use of both fast and effective methods for determining seeds humidity degree can aid in their preservation. With the objective of determining an appropriate methodology to determine the ipê-pity-savannah ( Tabebuia ochracea (Cham.) Standl.) seeds humidity, four lots of seeds collected in Machado-MG had their humidity level determined in two stages. In the first stage of the experiment greenhouse methods were tested at $105^{\circ} \mathrm{C} / 24 \mathrm{~h}$ with different repetitions and recipients weights. In the second stage the greenhouse method that resulted in smaller variation among the repetitions obtained in the first stage was compared with the microwave oven method using different procedures and times of exposure. The conditions of the greenhouse method that resulted in smaller variation of results in the determination of ipê-pity-savannah seeds humidity were $103^{\circ} \mathrm{C} / 17 \mathrm{~h}$ with the use of aluminum capsules and one-gram seed weight. The smallest variations of results between the greenhouse methodogy $103^{\circ} \mathrm{C} / 17 \mathrm{~h}$ and the microwave oven take place when the time period to determine the humidity of ipê- pity- savannah seeds is five minutes.
\end{abstract}

Index terms: Greenhouse, ipê-pity-savannah, humitidy degree, forest species, microwave, Tabebuia ochracea.

(Recebido para publicação em 11 de setembro de 2003 e aprovado em 22 de junho de 2004)

\section{INTRODUÇÃO}

A espécie T. ochracea (Cham.) Standl., conhecida como ipê-do-cerrado, é encontrada em várias regiões do Brasil, como Mato Grosso do Sul, Goiás, São Paulo, Paraná e Minas Gerais. As árvores são utilizadas, principalmente, para ornamentação. Como planta adaptada a terrenos secos, essa espécie é útil para plantios em áreas degradadas de preservação permanente (LORENZI, 1992). A espécie é propagada por sementes, que podem se deteriorar rapidamente, uma vez que são dispersas com alto grau de umidade (GEMAQUE, 1999).
Para que se possa obter sementes de alta qualidade, é necessário observar vários aspectos durante a realização dos processos a que essas sementes são submetidas, antes de sua utilização nos plantios. Um dos aspectos mais importantes é o grau de umidade das sementes, já que o conhecimento dessa característica permite a escolha dos procedimentos mais adequados para a colheita, secagem, beneficiamento e armazenamento, o que possibilita a preservação da qualidade física, fisiológica e sanitária. Determinações periódicas do grau de umidade, entre a colheita e a utilização nos plantios, permitem a identificação de problemas que porventura ocorram ao

1. Graduanda do curso de Agronomia da Universidade Federal de Lavras/UFLA, Caixa Postal 3037 - 37200-000 - Lavras, MG.

2. Professora Titular do Departamento de Agricultura/Setor Sementes, UFLA

3. Doutoranda da Fitotecnia, UFLA. 
longo das diferentes fases do processamento e possibilitam a adoção de medidas adequadas para a sua solução (MARCOS FILHO et al., 1987).

Há poucas informações sobre as formas mais adequadas de determinação do grau de umidade para a maioria das espécies florestais nativas, como o ipê-docerrado, o que tem gerado dificuldades em padronizar os procedimentos básicos de comparação dos resultados de umidade (RAMOS e BIANCHETTI, 1990). De acordo com ASAE (1992), há uma grande diversidade de metodologias oficiais para determinação do grau de umidade para uma mesma espécie, não havendo um consenso geral entre os países sobre qual é a mais indicada.

As Regras para Análise de Sementes (BRASIL, 1992) recomendam para todas as espécies florestais a utilização dos métodos de estufa a $105^{\circ} \mathrm{C} / 24 \mathrm{~h}$, $103^{\circ} \mathrm{C} / 17 \mathrm{~h}$ e $130^{\circ} \mathrm{C} / 17 \mathrm{~h}$ para a determinação do grau de umidade das sementes. O método adotado como oficial pela ISTA (1993), para a determinação do grau de umidade das sementes florestais, consiste na utilização de estufa com circulação de ar e temperatura de $103^{\circ} \mathrm{C} \pm$ $2^{\circ} \mathrm{C}$ durante $17 \pm 1$ hora; no entanto, devido à grande variação encontrada entre as espécies florestais, é necessária a verificação de qual metodologia é a mais eficiente para cada espécie em particular. Além disso, os métodos preconizados demandam tempo e impedem a utilização imediata do lote na umidade definida. A utilização de métodos mais rápidos, como o método do forno de microondas, é uma alternativa que vem sendo desenvolvida com eficiência para muitas espécies (CARVALHO et al., 1997).

Bonner (1991) obteve grande sucesso na determinação de umidade em sementes de espécies arbóreas, especialmente aquelas ortodoxas, quando utilizou o método de secagem em forno de microondas. Segundo o autor, se houver necessidade de uma determinação rápida de umidade, esse pode ser considerado como um dos poucos métodos eficientes disponíveis. Da mesma forma, Ramos et al. (2000) observaram que a secagem em estufa a $130^{\circ} \mathrm{C}$ e a secagem em forno de microondas, visando a determinar o grau de umidade em sementes de Parkia multijuga Benth., podem ser utilizadas como métodos alternativos rápidos, sendo tão precisos quanto o método oficial a $105^{\circ} \mathrm{C} / 24 \mathrm{~h}$.

Este trabalho foi desenvolvido com os seguintes objetivos: avaliar qual método de estufa é o mais indicado para determinar a umidade de sementes de ipê-docerrado e verificar a possibilidade de utilização de forno de microondas para a determinação rápida da umidade dessas sementes.

\section{MATERIAL E MÉTODOS}

O trabalho foi desenvolvido no Laboratório de Análise de Sementes e no Laboratório de Sementes Florestais da Universidade Federal de Lavras (UFLA). Foram utilizadas sementes de ipê-do-cerrado coletadas aleatoriamente de 60 árvores na região de Machado-MG, originadas de frutos colhidos em diferentes estádios de maturação, que constituíram os lotes: lote 1 - frutos abertos colhidos no final do período de maturação; lote 2 - frutos fechados; lote 3 - frutos iniciando abertura da vagem; lote 4 - sementes coletadas na projeção da copa após deiscência dos frutos. O experimento envolveu duas etapas. Na primeira etapa, foram comparados os métodos de estufa a $105^{\circ} \mathrm{C} / 24 \mathrm{~h}$ e a $103^{\circ} \mathrm{C} / 17 \mathrm{~h}$ (BRASIL, 1992), os efeitos de diferentes recipientes (papel-alumínio - 19,4 cm de comprimento por 17,7 de largura e cápsulas de alumínio - 5,5 cm de diâmetro e 3,5 cm de altura) e dos pesos das repetições (de 1 e 4 gramas). Foram assim obtidos os tratamentos: 1) 1 grama de sementes em cápsulas de alumínio a $105^{\circ} \mathrm{C} / 24 \mathrm{~h}$; 2) 1 grama de sementes em cápsulas de alumínio a $103^{\circ} \mathrm{C} / 17 \mathrm{~h}$; 3) 1 grama de sementes em papelalumínio a $105^{\circ} \mathrm{C} / 24 \mathrm{~h}$; 4) 1 grama de sementes em papelalumínio a $1030 \mathrm{C} / 17 \mathrm{~h}$; 5) 4 gramas de sementes em cápsulas de alumínio a $105^{\circ} \mathrm{C} / 24 \mathrm{~h}$; 6) 4 gramas de sementes em cápsulas de alumínio a $103^{\circ} \mathrm{C} / 17 \mathrm{~h}$; 7) 4 gramas de sementes em papel-alumínio a $105^{\circ} \mathrm{C} / 24 \mathrm{~h}$; 8) 4 gramas de sementes em papel-alumínio a $103^{\circ} \mathrm{C} / 17 \mathrm{~h}$.

As sementes de cada tratamento foram pesadas e colocadas nos recipientes para obtenção de peso da matéria fresca e mantidas em estufa por 24 horas a 105 oC e 17 horas a 1030 . Após esse período, os recipientes contendo as sementes foram fechados e colocados em dessecador durante 30 minutos para resfriamento, sendo, então, novamente pesados para obtenção do peso da matéria seca das sementes. O grau de umidade das sementes foi determinado de acordo com as RAS (BRASIL, 1992). Foi utilizado o delineamento inteiramente casualizado com quatro repetições.

O tratamento que proporcionou uma menor variação entre repetições foi utilizado como padrão para o estudo do grau de umidade em forno de microondas. Foi utilizado o programa SANEST (Sistema de Análise Estatística para Microcomputadores) para a análise de variância dos dados obtidos (ZONTA e MACHADO, 1996), obtendo-se os erros entre repetições.

Na segunda etapa, foi avaliada a possibilidade de utilização do forno de microondas na determinação do grau de umidade das sementes de ipê-do-cerrado. Foram utilizadas sementes dos quatro lotes já descritos, umedecidas artificialmente ou não, num total de oito lo- 
tes. Para o umedecimento, as sementes de cada lote (1 a 4) foram colocadas sob substrato de papel-toalha em bandejas de plástico em germinadores tipo Mangelsdorf a $30^{\circ} \mathrm{C}$ e $98 \%$ de umidade relativa por 24 horas. Após esse período, as sementes umedecidas foram acondicionadas em sacos plásticos e mantidas por três dias em ambiente de laboratório, para homogeneização da umidade. Dessa forma, foram obtidos dois níveis de umidade para os quatro lotes que consistiram as subamostras.

Para a determinação da umidade no forno de microondas, as sementes de cada repetição das oito subamostras foram acondicionadas em formas de papel-alumínio (19,4 cm de comprimento por 17,7 de largura), pesadas e colocadas em forno de microondas da marca Brastemp na potência de $490 \mathrm{w}$, por diferentes tempos.

Foram testadas duas metodologias para a utilização do forno de microondas. A primeira metodologia, chamada de Amostra Variável, consistiu da exposição das sementes por períodos de 5, 7, 9, 11 e 13 minutos, utilizando diferentes subamostras para cada período citado. Na segunda metodologia, chamada Amostra Única, foi utilizada uma mesma amostra para todos os períodos citados. Para isso, os recipientes com as sementes foram inicialmente colocados por 5 minutos em forno de microondas, resfriados em dessecador por 5 minutos, sendo as sementes pesadas rapidamente, retornando ao forno de microondas por mais 2 minutos, totalizando 7 minutos e assim consecutivamente, de 2 em 2 minutos, até totalizar 13 minutos de exposição. Foram utilizadas quatro repetições de 1 (um) grama para cada subamostra.

Conforme recomendações de Carvalho et al. (1997), foi utilizado um becker contendo $125 \mathrm{ml}$ de água para manter uma distribuição homogênea dos elétrons no interior do forno. O forno de microondas foi resfriado antes de se colocar uma nova amostra.

O delineamento utilizado foi o inteiramente casualizado em esquema fatorial $2 \times 8 \times 5+1$, sendo duas metodologias de utilização ao forno microondas (amostra variável e única), oito lotes, cinco tempos de exposição ao microondas e o método de estufa padrão.

Foi utilizado o programa SANEST (Sistema de Análise Estatística para Microcomputadores) com o teste Bilateral de Dunnett, para análise dos dados obtidos (ZONTA e MACHADO, 1996).

\section{RESULTADOS E DISCUSSÃO}

Na comparação dos diferentes tratamentos da primeira etapa, foram analisadas as variações entre repetições, determinando-se o tratamento que propiciou menor erro e maior precisão na avaliação da umidade. O uso do método da estufa $1030 \mathrm{C} / 17 \mathrm{~h}$ em cápsulas de alumínio com peso das repetições de 1 (um) grama propiciou o menor erro experimental - 0,10843 (Tabela 1). No entanto, para as mesmas condições de peso e temperatura, o uso do papel de alumínio propiciou o maior erro, ou seja, de - 10,0372.

TABELA 1 - Valores de erros obtidos para os diferentes tratamentos realizados para determinação da umidade de sementes de ipê-do-cerrado (Tabebuia ochracea). UFLA, Lavras - MG, 2001.

\begin{tabular}{ccc}
\hline Subamostras & Tratamento & Erro \\
\hline 1 & 1 grama - cápsula de alumínio $-105^{\circ} \mathrm{C} / 24 \mathrm{~h}$ & 3.5393 \\
2 & 1 grama - cápsula de alumínio $-103^{\circ} \mathrm{C} / 17 \mathrm{~h}$ & -0.1084 \\
3 & 1 grama - papel alumínio $-105^{\circ} \mathrm{C} / 24 \mathrm{~h}$ & -3.4309 \\
4 & 1 grama - papel alumínio $-103^{\circ} \mathrm{C} / 17 \mathrm{~h}$ & -10.0372 \\
5 & 4 gramas - cápsula de alumínio $-105^{\circ} \mathrm{C} / 24 \mathrm{~h}$ & 8.3101 \\
6 & 4 gramas - cápsula de alumínio $-103^{\circ} \mathrm{C} / 17 \mathrm{~h}$ & 3.3767 \\
7 & 4 gramas - papel-alumínio $-105^{\circ} \mathrm{C} / 24 \mathrm{~h}$ & -1.0843 \\
8 & 4 gramas - papel-alumínio $-103^{\circ} \mathrm{C} / 17 \mathrm{~h}$ & 0.2478 \\
\hline
\end{tabular}


Dependendo do método e do peso de sementes utilizado, a resposta à utilização de recipiente é variável, havendo uma interação significativa entre os parâmetros analisados (dados não mostrados). Campos e Tillmann (1996) e Ramos et al. (2000) observaram também que dependendo do método utilizado para determinação da umidade, pode haver maior ou menor variação de resultados.

Na Tabela 2 podem ser observados os valores médios obtidos na determinação do grau de umidade pelos diferentes métodos para cada lote de sementes de ipê-do-cerrado. Apenas para o lote 1, foram detectadas diferenças estatísticas entre os dois métodos testados.

A variação de resultados entre diferentes métodos de secagem em estufa tem sido apontada em estudos realizados para espécies de grandes culturas, como milho, trigo, arroz, soja e cebola (CAMPOS e TILLMANN, 1996). Esses estudos confirmam que os graus de umidade determinados pelos vários métodos podem diferir e que essas diferenças são influenciadas pelo tempo de exposição ao calor.

Na segunda etapa, todos os lotes submetidos ao método de microondas permitiram uma remoção de água proporcional à quantidade de água presente nas sementes (Tabela 3). Teoricamente, os métodos de determinação do grau de umidade em estufa removem a água absorvida e a adsorvida (livre), mas não a água de constituição (HENDERSON, 1991). A determinação do grau de umidade com a utilização de métodos de estufa é dificultado, porque na remoção da água livre, alguma quantidade de água de constituição e materiais voláteis são provavelmente liberados (VEASEY, 1971).

A quantidade de água retirada das sementes submetidas aos tempos e metodologias de uso do forno de microondas variou em relação ao método de estufa em alguns lotes (Tabela 3). Essa variação pode ter sido in- fluenciada pelas diferentes épocas de colheita e teores de água das sementes de cada lote. Oxley e Pixton (1960), avaliando o grau de umidade de sementes de cereais, constataram diferentes resultados de umidade em cinco métodos de estufa, inferindo-se que a determinação da umidade pode ser influenciada pelas diferenças em lotes obtidos em diferentes condições.

Para o lote 1 (sementes coletadas com os frutos abertos), os resultados da determinação da umidade pelo método de microondas por 5 minutos, tanto para a metodologia com amostras variáveis como para a de amostra única de sementes e também os tempos de exposição ao microondas com amostra variável de 7 e 11, coincidiram com os resultados da determinação realizada na estufa. Já para o lote 5 (lote 1 umedecido artificialmente), houve diferenças significativas entre os métodos de estufa e microondas com metodologia de amostra variável nos tempos de 9 e 11 (Tabela 3).

Em se tratando do lote 2 (sementes ainda nos frutos fechados e armazenados em condições de laboratório), apenas o tempo de 5 minutos com amostra variável não diferiu com a estufa. No entanto, quando as sementes foram umedecidas artificialmente (lote 6), o tempo de 5 minutos com amostras variáveis, e os tempos 5, 7, 11 e 13 minutos, com amostra única, não diferiram do método de estufa.

No lote 3 (sementes coletadas de frutos contendo pequenas rachaduras), os resultados de umidade dos tempos de 5 e 7 minutos utilizando amostra única no forno de microondas coincidiram com os resultados obtidos na estufa. Porém, quando as sementes foram umedecidas (lote 7), os resultados obtidos com os tempos de secagem no microondas de 5 e 9 minutos, com amostras variáveis, e todos os tempos de secagem com amostra única não apresentaram diferenças significativas em relação aos resultados do método de estufa.

TABELA 2 - Dados médios obtidos na determinação do grau de umidade dos lotes de sementes de ipê-do-cerrado (Tabebuia ochracea.) para cada método de estufa. UFLA, Lavras - MG, 2001.

\begin{tabular}{ccccc}
\hline \multirow{2}{*}{ Métodos de Estufa } & \multicolumn{5}{c}{ Lotes* $^{*} \mathbf{3}$} & $\mathbf{4}$ \\
\cline { 2 - 5 } & $\mathbf{1}$ & $\mathbf{2}$ & $8,37 \mathrm{a}$ & $7,92 \mathrm{a}$ \\
\hline $103^{\circ} \mathrm{C} / 17 \mathrm{~h}$ & $8,62 \mathrm{a}$ & $8,20 \mathrm{a}$ & $7,92 \mathrm{a}$ & $7,66 \mathrm{a}$ \\
$105^{\circ} \mathrm{C} / 24 \mathrm{~h}$ & $7,91 \mathrm{~b}$ & $7,90 \mathrm{a}$ & $\mathrm{3}$ \\
\hline
\end{tabular}

*Médias seguidas por letra distintas na mesma coluna diferem entre si pelo teste de Tukey a $5 \%$ de probabilidade. 
TABELA 3 - Porcentagem média do grau de umidade dos lotes de sementes de ipê-do-cerrado (Tabebuia ochracea), comparados com o tratamento de estufa. UFLA, Lavras - MG, 2001.

\begin{tabular}{lcccccccc}
\hline \multirow{2}{*}{ Tratamentos } & \multicolumn{7}{c}{ Lotes } \\
\cline { 2 - 9 } & $\mathbf{1}$ & $\mathbf{2}$ & $\mathbf{3}$ & $\mathbf{4}$ & $\mathbf{5}$ & $\mathbf{6}$ & $\mathbf{7}$ & $\mathbf{8}$ \\
\hline Estufa & 7.50 & 7.00 & 7.96 & 9.45 & 19.10 & 29.85 & 18.56 & 25.25 \\
\hline Variável 5 & $7.03 \mathrm{~ns}$ & $11.38 \mathrm{~ns}$ & $18.99^{*}$ & $10.44 \mathrm{~ns}$ & $21.40 \mathrm{~ns}$ & $32.83 \mathrm{~ns}$ & $22.87 \mathrm{~ns}$ & $30.34 \mathrm{~ns}$ \\
Variável 7 & $12.40 \mathrm{~ns}$ & $16.83^{*}$ & $16.83^{*}$ & $11.99 \mathrm{~ns}$ & $17.48 \mathrm{~ns}$ & $14.85^{*}$ & $28.05^{*}$ & $28.35 \mathrm{~ns}$ \\
Variável 9 & $16.41^{*}$ & $19.80^{*}$ & $17.60^{*}$ & $14.85 \mathrm{~ns}$ & $27.73^{*}$ & $19.36^{*}$ & $24.93 \mathrm{~ns}$ & $10.00^{*}$ \\
Variável 11 & $14.02 \mathrm{~ns}$ & $18.41^{*}$ & $16.59^{*}$ & $15.43 \mathrm{~ns}$ & $26.05^{*}$ & $37.81^{*}$ & $27.05^{*}$ & $36.31^{*}$ \\
Variável 13 & $15.50^{*}$ & $23.12^{*}$ & $18.00^{*}$ & $15.41 \mathrm{~ns}$ & $24.75 \mathrm{~ns}$ & $40.05^{*}$ & $29.00^{*}$ & $37.69 *$ \\
Única 5 & $6.02 \mathrm{~ns}$ & $15.50^{*}$ & $14.25 \mathrm{~ns}$ & $12.87 \mathrm{~ns}$ & $19.05 \mathrm{~ns}$ & $35.17 \mathrm{~ns}$ & $20.29 \mathrm{~ns}$ & $25.81 \mathrm{~ns}$ \\
Única 7 & $14.92^{*}$ & $15.49^{*}$ & $13.94 \mathrm{~ns}$ & $17.32^{*}$ & $20.00 \mathrm{~ns}$ & $36.18 \mathrm{~ns}$ & $21.28 \mathrm{~ns}$ & $26.86 \mathrm{~ns}$ \\
Única 9 & $15.92^{*}$ & $18.00^{*}$ & $15.69^{*}$ & $19.80^{*}$ & $22.00 \mathrm{~ns}$ & $39.69 *$ & $23.76 \mathrm{~ns}$ & $28.85 \mathrm{~ns}$ \\
Única 11 & $14.40^{*}$ & $18.00^{*}$ & $16.67 *$ & $22.27 *$ & $21.00 \mathrm{~ns}$ & $36.68 \mathrm{~ns}$ & $21.78 \mathrm{~ns}$ & $27.85 \mathrm{~ns}$ \\
Única 13 & $18.40^{*}$ & $20.48^{*}$ & $17.67 *$ & $20.79 *$ & $20.05 \mathrm{~ns}$ & $36.68 \mathrm{~ns}$ & $22.27 \mathrm{~ns}$ & $27.85 \mathrm{~ns}$ \\
\hline
\end{tabular}

*Tratamentos que diferem da estufa ao nível de $5 \%$ de probalidade pelo teste Bilateral de Dunnett.

Ns - Tratamentos que não diferem da estufa ao nível de $5 \%$ de probalidade pelo teste Bilateral de Dunnett. $\mathrm{CV}=\mathbf{1 2 . 5 1 \%}$

Quando as sementes foram coletadas no chão e armazenadas em ambiente de laboratório (lote 4), os graus de umidade obtidos por todos os tempos de secagem com amostras variáveis, e o tempo de 5 minutos, com amostra única, no forno de microondas, não foram diferentes daquele obtido pelo método de estufa. O mesmo não foi observado quando esse lote foi umedecido artificialmente (lote 8), pois, para amostra única, foi observado que os resultados obtidos em todos os tempos de secagem não apresentaram diferenças significativas em relação aos resultados obtidos com o método de estufa e quando se utilizou a metodologia de amostra variável, apenas os tempos de 5 e 7 minutos coincidiram com a estufa (Tabela 3).

Nota-se que o tempo de 5 minutos, independente da metodologia utilizada para o forno de microondas (amostra variável ou amostra única), propicia resultados mais próximos aos encontrados pelo método de estufa $103^{\circ} \mathrm{C} / 17 \mathrm{~h}$.

Segundo Casada et al. (1983), o fator tempo é essencial para utilização do método de microondas, para evitar a destruição das amostras pela exposição prolongada à radiação e, ao mesmo tempo, para promover a elevação da temperatura do produto e a vaporização da água, ou seja, propiciar a transformação do calor sensível em calor de vaporização.

Outro aspecto a ser considerado é a relação entre o tempo de permanência das sementes no microondas e o teor de água das sementes (FRANDOLOSO et al., 1998). De acordo com Institute of Food Tecnologists (1989), quanto maior for o teor de água, menor será a profundidade de penetração das microondas e a uniformidade do índice de aquecimento. Por outro lado, os produtos com baixo teor de água aquecem-se mais uniformemente pela baixa capacidade térmica.

Por remover a água do interior da semente rapidamente, a secagem em microondas pode reduzir a perda de componentes voláteis, quando comparada à secagem em fornos convencionais (GRABE, 1989).

Na comparação entre os resultados obtidos utilizando amostra variável e amostra única (Tabela 3), pode ser observado um maior número de variações significativas de tratamentos que diferem do método de estufa quando se utiliza amostra variável. Dessa forma, a metodologia de amostra única provavelmente seria mais adequada para a determinação da umidade em sementes de ipê-do-cerrado pelo método de microondas. No entanto, há necessidade de maior refinamento na técnica de microon- 
das para que os resultados sejam utilizados na prática, em substituição ao método de estufa, uma vez que variações superiores a 7\% de umidade foram consideradas estatisticamente não-significativas.

Valentini et al. (1998) sugerem para sementes de milho a realização de experimentos que empregam diversos modelos de aparelhos de microondas e diferentes metodologias para comparação de resultados. Da mesma forma, estudos envolvendo um refinamento da técnica de microondas para determinação da umidade de sementes de ipê-do-cerrado devem ser efetuados, para que se tenha uma recomendação definitiva da metodologia a ser empregada.

\section{CONCLUSÕES}

O método de estufa mais indicado para sementes de ipê-do-cerrado foi $103^{\circ} \mathrm{C} / 17 \mathrm{~h}$, utilizando recipientes de cápsula de alumínio com peso de repetições das sementes de 1 (um) grama.

As menores variações de resultados entre a metodologia de estufa $103^{\circ} \mathrm{C} / 17 \mathrm{~h}$ e forno de microondas ocorreram quando se utilizou o tempo de 5 minutos para determinação da umidade de sementes de ipê-docerrado; entretanto, há necessidade de maior refinamento na técnica de microondas para que esse método seja recomendado rotineiramente.

\section{REFERÊNCIAS BIBLIOGRÁFICAS}

AMERICAN SOCIETY OF AGRICULTURAL ENGINEERS. Moisture measurement unground grain and seeds 1992. 30. ed. Saint Joseph, 1992. 404 p. (ASAE Standard and seeds. ASAE, S. 353. 2).

BRASIL. Ministério da Agricultura e da Reforma Agrária. Regras para análise de sementes. Brasília: SNDA/DNPV/CLAV, 1992. 185 p.

BONNER, F. T. Measure of moisture content. In: GORDON, A. G.; GOSLING, P.; WONG, S. P. (Eds.). Tree and shrub seed hanbook. Zurich: The International Seed Testing Association, 1991. p. 12-17.

CAMPOS, V. C.; TILLMANN, M. A. A. Comparação entre os métodos oficiais de estufa para determinação do grau de umidade de sementes. Revista Brasileira de Sementes, Brasília, v. 18, n. 1, p.134-137, 1996.
CARVALHO, L. R. de; DAVIDE, A. C.; MALAVASI, $M$. de M. Determinação do grau de umidade de sementes de espécies florestais utilizando forno de microondas. 1997. Graduação (Monografia) - Universidade Federal de Lavras, Lavras, 1997.

CASADA, M. E. et al. Moisture content as a function of temperature rise under microwave radiation. Saint Joseph: ASAE, 1983.

FRANDOLOSO, V.; TILLMANN, M. A.; BAUDET, L. Determinação do grau de umidade de sementes de cebola, cenoura e tomate em forno de microondas. Revista Brasileira de Sementes, Brasília, v. 20, n. 2, p. 286-295, 1998.

GEMAQUE, R. C. R. Maturação, tolerância à dessecação e alterações na qualidade fisiológica em sementes de ipê-roxo (Tabebuia impetiginosa (Mart.) Standl.) envelhecidas artificialmente. 1999. 93 p. Dissertação (Mestrado em Ciências Florestais) - Universidade Federal de Lavras, Lavras, 1999.

GRABE, D. F. Measurement of seed moisture. In: STANWOOD, P. C.; McDONALD, M. B. Seed moisture. Madison: CSSA, 1989. p. 69-92.

HENDERSON, S. Sources of variation in the determination of misture content of cereal grains and oilseeds by ovendrying methods. Phostharvest News and Information, Wallingford, v. 2, n. 5, p. 335-339, 1991.

INTERNATIONAL

SEED

TESTING ASSOCIATION. International rules for seed testing: rules 1992. Seed Science and technology, Zurich, v. 21, p. 231, 1993.

INSTITUTE OF FOOD TECNOLOGISTS. Microwave food processing. Food Technology, Chicago, v. 43, n. 1, p. 117-126, 1989.

LORENZI, H. Árvores brasileiras: manual de identificação e cultivo de plantas arbóreas nativas do Brasil. Nova Odessa: Plantarum, 1992. 368 p.

MARCOS FILHO, J.; CICERO, S. M.; SILVA, W. R. Avaliação da qualidade das sementes. Piracicaba: FEALQ, 1987. $230 \mathrm{p}$.

OXLEY, T. A.; PIXTON, J. L. Determination of moisture content in cereals: II. errors in the determination by oven drying of known changes in moisture content. Journal of the Science of Food and Agriculture, London, v. 11, n. 6, p. 315-320, 1960. 
RAMOS, A.; BIANCHETTI, A. Metodologia para determinação do teor de umidade de sementes de Aracauraia angustifolia (Bert.) Kuntze. Revista Brasileira de Sementes, Brasília, v. 3, p. 9-16, 1990.

RAMOS, F. N. et al. Comparação entre métodos de secagem na determinação do grau de umidade em sementes de Parkia multijuga Benth. (Leguminosa Mimonoideae). Revista Árvore, Viçosa, v. 24, n. 2, p. 175-179, 2000.
VALENTINI, S. R. T.; CASTRO, M. F. P. M. de; ALMEIDA, F. H. de. Determinação do teor de umidade de milho utilizando aparelho microondas. Ciência e Tecnologia dos Alimentos, Campinas, v. 18, n. 2, p. 237-240, maio/jul. 1998.

VEASEY, D. P. Effect of ambient conditions on oven methods of moisture measurement. Milling, London, v. 153, n. 1, p. 17-18, 1971.

ZONTA, E. P.; MACHADO, A. A. Sistema de análise estatística para microcomputadores. Pelotas: UFPEL, 1996. 